GLOBAL CHILD HEALTH

\title{
Improving drug use for children in the developing world
}

\author{
S A Beggs, N E Cranswick, M D Reed
}

Arch Dis Child 2005;90:1091-1093. doi: 10.1136/adc.2005.076703

Children differ significantly from adults in the way they absorb, metabolise, and excrete drugs.' These parameters also vary as children grow from neonates through to adolescence. The practical implications and challenges that this presents are well know to anyone who is involved in the medical management of sick children. The importance of paediatric medication safety and efficacy has been gaining increasing attention in the developed world over the past decade. The United States has introduced a carrot and stick approach to increase research into medications for children with the "paediatric exclusivity provision" and the "paediatric rule". The European Union is also investigating ways of improving the availability of medications for children. Unfortunately, this increased focus on appropriate medicines for children, which has occurred in the developed world, has not been mirrored in developing nations. Currently more than 10 million children under the age of 5 years die each year, ${ }^{2}{ }^{3}$ with only six countries accounting for $50 \%$ of these deaths. The majority of these deaths are from treatable or preventable diseases. ${ }^{4}$ The developed world has a moral and ethical obligation to share its gains with the children of the world.

See end of article for authors' affiliations

Correspondence to: Dr S Beggs, Clinical Pharmacology, 5th Floor, Main Building, Royal Children's Hospital Flemington Rd, Parkville, Victoria, Australia, 3052; sean.beggs@rch.org.au

Accepted 18 May 2005
A s significant advances are made in the treatment of children in the developed world it is time to expand our areas of research to improve the health care of children in resource poor settings. As a priority we need to focus on a few key areas where we can affect a significant impact: the rational use of medications in children, including guidelines for appropriate drug choice and use in paediatrics; the development of appropriate formulations for children, and where such formulations are not available, guidelines for preparation of extemporaneous formulations appropriate for resource poor settings; and finally the methods by which medications are purchased and distributed within each country. It is also important to recognise that effective methods used to maintain compliance with drug administration may also be specific to the culture and belief system in a country.

It is paramount that all interventions are individualised to the needs of a given country or even a given region within a country, as one size will not fit all. The importance of a country specific assessment cannot be overemphasised. This glaring need is underscored by assessing the burden of disease for children under 5 years of age, as measured by mortality. For example, the causes of under 5 mortality in sub-Saharan Africa are: neonatal causes (25\%), malaria $(22 \%)$, pneumonia $(21 \%)$, diarrhoea $(20 \%)$, and AIDS $(8 \%) .{ }^{4}$ On the surface this aggregate might suggest that the priority areas for all countries in the region should be malaria and AIDS. This would be inappropriate as some countries in subSaharan Africa have very little malaria, others very few AIDS deaths, while some are severely affected by both. ${ }^{5}$ One plan for the enhancement of paediatric therapeutics will not be applicable to all countries.

The irrational use of medications is a significant problem worldwide. It is estimated that 25$75 \%$ of antibiotic prescriptions in teaching hospitals are inappropriate and that half of the worlds 15 billion injections are unsafe. ${ }^{6}$ The rational use of medication starts with choosing appropriate medications in the first instance. The WHO model essential medicine list (EML) helps countries develop their own EML with the aim of improving drug use through rational choice. The EML has been in existence for more than 25 years. It has proven to be a very successful public health initiative, with over 156 countries adopting the concept and developing their own EML. ${ }^{6}$ Currently however, both the WHO model EML and formulary lack a paediatric focus. This is shown by the fact that of the 160 medication listings on the core list that could include a paediatric formulation, only 47 do so. ${ }^{7}$ The Expert Committee on the Selection and Use of Essential Medicines have themselves noted the need for a special review of the use of medications in paediatrics. ${ }^{8}$

The development of a paediatric specific essential medicine list would have a number of benefits. It would increase the awareness of the need for paediatric specific medications and formulations, and highlight areas of priority where medications or formulations are lacking. WHO and UNICEF only promote the use of medications that are on the EML, so a paediatric list would also stimulate pharmaceutical companies to produce paediatric medications. Through increasing the availability of paediatric oral formulations, such a list could also decrease the reliance on parenteral medications in children and thus the morbidity associated with their use. The need for paediatric specific formularies and drug references is shown by the fact that many countries have recently produced such publications, namely Medicines for children ${ }^{9}$ in the UK and Paediatric pharmacopoeia ${ }^{10}$ in Australia.

The compilation of an appropriate essential medicines list for children is just the first step to improving the use of medicines for the world's children. Regardless of how comprehensive or practical such a list is, it will have little impact on 
child health if significant numbers of children worldwide continue to be denied access to these important, listed medications. Currently it is estimated that a third of the world's population, 2 billion people, do not have regular access to essential medicines, ${ }^{11}$ this percentage rises to $50 \%$ in the poorest parts of Africa and Asia. ${ }^{12}$ The Commission on Macroeconomics and Health estimates that 8 million deaths a year could be prevented by 2015 , through merely scaling up essential health services. The majority of such essential health services require reliable access to essential medicines. ${ }^{13}$ To improve access to essential medicines for children we have to strengthen health services for children in developing countries and ensure that they have a high priority. As identified by the Millennium Project Task force on HIV/AIDS, Malaria, TB and Access to Essential Medicines, the grading up of health facilities is very complex. ${ }^{14}$ It requires concerted and prolonged commitment from multiple stakeholders, including international donors and recipient governments. A coordinated, long term, all encompassing approach needs to replace the often fragmented single programme, short term and unpredictable approach that currently occurs. Developed countries need to commit to providing development aid while developing countries need to realise the importance of investing in health. Individual countries themselves must initiate these measures or else they are destined to fail.

The cost of medications is one of the key barriers to their full access. In developing and transitional economies, 50-90\% of medications are paid for directly by patients. ${ }^{15}$ This disadvantages the poorest and most vulnerable in a community, such as children, leading to delays in or absence of seeking health care and subsequent under-treated morbidity and mortality. User pay systems need to be abolished to remove a significant barrier to access. The price of new medications in particular has become a significant concern in recent years. Anti-retroviral medications are an excellent example of how new essential medicines can be priced outside the grasp of the countries that need them most. Drug development is an expensive process. Patent laws have been implemented to allow manufactures time to recoup costs and make profits before they are exposed to competition. Members of the World Trade Organisation are bound by the agreement on Trade-Related Aspects of Intellectual Property Rights (TRIPS), which established a global minimum for patent protection.

Patent protection is a two edged sword when it comes to the pharmaceutical industry and the development of new medications. On the one hand, patents stimulate research and development of new and important therapeutic advances, while on the other hand they decrease competition from generics, thus maintaining the high cost of medicines. The international community has attempted to address this issue through the Doha Declaration on the TRIPS Agreement in 2001 and the Paragraph 6 decision in 2003. These agreements theoretically enable countries with public health needs and insufficient manufacturing capacity to import lower cost products from other countries. This will become increasingly difficult however as countries such as India implement laws preventing the reverse engineering of pharmaceuticals and sale of cheaper generic equivalents. The Indian generics industry has played a major role in reducing the cost of treating an AIDS patient in the developing world, where it now costs $\$ 140$ per year compared with \$10 000-30 000 per year in Europe or the USA. ${ }^{16}$ The UK Department for International Development (DIFD) report, Access to medicines in under-served markets, ${ }^{16}$ provides a comprehensive review of this very complex area.

In addition to accessibility, an extremely important but often overlooked characteristic of essential medications is their available formulation(s) and storage requirements. The majority of medications worldwide are not formulated for easy or accurate administration to children. The lack of appropriate formulations for children makes dosing of medications in this population less precise and less safe than in adults. The younger the child the less likely there will be an appropriate formulation. ${ }^{17}$ The need for paediatric formulations has recently had increased publicity in relation to HIV medications. The WHO and non-government organisations, such as Médecins Sans Frontières, have been advocating strongly for industry to development paediatric anti-retroviral formulations. The problem of formulations is not limited to HIV medications, however; it is an issue for the majority of therapeutic drug classes used in children. It is important to convince industry of the need and value of developing paediatric formulations applicable to the developing world. It must be ensured that such formulations are safe. The hundreds of child fatalities from diethylene glycol poisoning through the preparations of liquid formulations in Nigeria, ${ }^{18}$ Bangladesh, ${ }^{19}$ India, ${ }^{20}$ and $\mathrm{Haiti}^{21}$ in the 1990s serve as poignant and recent reminders of the disasters that can occur when paediatric formulations are not prepared safely.

Relying solely on industry will take time, and appropriate formulations are required now. In the absence of commercially prepared formulations appropriate for paediatrics, a compendium of analytically defined stability recommendations encompassing multiple time and temperature conditions for extemporaneous formulations of "essential" medications must be undertaken. This information is available for many compounds used in developed countries (for example, Pediatric drug formulations ${ }^{22}$ ); unfortunately, these resources are generally not applicable to developing countries. The methods outlined and resources required are often not feasible in resource poor settings. Medication storage conditions and facilities (for example, refrigeration) that are routine in developed countries may not be easily accessible in developing countries, resulting in unacceptable wastage. Another problem with currently available references is their lack of focus on drugs used in developing countries as well as a lack of uniformity in stability testing methodology. These important deficiencies must be addressed in a methodical and coordinated fashion with a primary focus on practicality within resource poor settings. Research into the preparation and stability of extemporaneous formulations under multiple storage conditions appropriate for the developing world needs to be undertaken immediately.

Many obstacles to performing clinical research by local investigators and practitioners within developing countries exist, including a lack of resources and large clinical demands. Researchers in resource poor settings need to be supported and assisted by those from more affluent countries. There is a great need for research into the development of new treatments focused on neglected diseases, which plague developing countries. Of the 1393 new chemical entities developed over the past 25 years, only $1 \%$ have been aimed at these neglected diseases despite their significant burden of morbidity and mortality. ${ }^{23}$ This significant imbalance in research has lead to the term "10/90 gap" to underscore the fact that of the $\$ 70$ billion spent each year on global health research, less than $10 \%$ is spent on research into diseases that represent $90 \%$ of the global disease burden. ${ }^{24}$ Research into drug safety and efficacy appropriate to children in developing countries must focus on the established treatments used in the less developed countries as well as contemporary treatment regimens available in developed countries. We all have a responsibility to assist in such research while simultaneously ensuring strict adherence to defined ethical standards. 
A way to start addressing these issues would be through the formation of regional collaborations, or networks, such as North America-South America, Europe-Africa, JapanNorthern Asia, Australia-Asia Pacific. Such integrated alliances would allow the development of in-depth local knowledge that is not possible from a global level. Formal collaborative research units could be developed within these networks and they could also participate in the refinement of essential medicine lists appropriate for children. Education would be a useful approach for addressing as well as increasing the understanding and visibility of the many problems of pharmaceutical care in developing countries. Strategies could include mini training programmes for counterparts to study with established preceptors in their programme, and/or visiting professor programmes for intensive "hands-on" training by established individuals within target areas. Numerous organisations (for example, the WHO) support such experiences, but much, much more must be done now that embraces a larger segment of needy countries in a manner that ensures lasting effects. Another approach could include conferences hosted by organisations such as the WHO, National Institutes of Health, IUPHAR, DIA, International Network for Rational Drug Use, and Médecins Sans Frontières, focusing on the problems of children in developing countries, in the areas of hospital and ambulatory pharmacotherapeutics and pharmacovigilance.

In October 2002, paediatric clinical pharmacologists from around the globe met to form an international consortium to begin to address some of these issues. A public health working group was formed which committed the International Consortium of Paediatric Clinical Pharmacology (ICPCP) to addressing issues relating to child public health. Paediatric clinical pharmacology has the opportunity and the obligation to make a significant contribution to the health of the children of the world. Over the past three decades it has made significant progress in attempting to rescue the therapeutic orphan in the developed world. The skills, experience, and knowledge gained from this experience in the areas of research, advocacy, and policy must be put to invaluable use in addressing many of the health issues facing children in developing countries. This is the broad aim of the International Consortium of Paediatric Clinical Pharmacologists' Public Health Working Group.

\section{ACKNOWLEDGEMENTS}

Members of the International Consortium of Paediatric Clinical Pharmacology public health working group: Drs Jack Aranda, USA; Michael Christensen, USA; Noel Cranswick (co-chair), Australia; Ralph Gorodisher, Israel; George Giacoia, USA; Kalle Hoppu Finland, Michael D. Reed (co-chair), USA, John Wilson, USA.

\section{Authors' affiliations}

S A Beggs, N E Cranswick, Clinical Pharmacology, Royal Children's Hospital, Melbourne, Australia

M D Reed, Dept of Paediatrics, School of Medicine, Case Western Reserve University, Cleveland, Ohio, USA
Funding: Dr Reed is supported by a Pediatric Pharmacology Research Unit grant from the National Institute of Child Health and Human Development (HD31323-10)

Competing interests: none declared

\section{REFERENCES}

1 Kearns GL, Abdel-Rahman SM, Alander SW, et al. Developmental pharmacology-drug disposition, action, and therapy in infants and children. N Engl J Med 2003;349:1 157-67.

2 Ahmad OB, Lopez AD, Inove M. The decline in child mortality: a reappraisal. Bull World Health Organ 2000;78:1175-91.

3 WHO. The world health report 2002: reducing the risks, promoting healthy life. Geneva: World Health Organization, 2002.

4 Black RE, Morris SS, Bryce J. Where and why are 10 million children dying every year? Lancet 2003;361:2226-34.

5 Morris SS, Black RE, Tomaskovic L. Predicting the distribution of under-five deaths by cause in countries without adequate vital registration systems. Int J Epidemiol 2003;32:1041-51.

6 Quick JD, Hogerzeil HV, Velasquez G, et al. Twenty-five years of essential medicines. Bull World Health Organ 2002;80:913-14.

7 WHO. Essential medicines: WHO model list, 13th edn. Geneva: World Health Organization, 2003.

8 WHO. The selection and use of essential medicines: report of the WHO Expert Committee. Geneva: World Health Organization, 2003, http:// www.who.int/medicines/organization/par/edl/expertcomm 13.shtm (accessed 21 May 2004).

9 RCPCH, NPPG. Medicines for children, 2nd edn. London: RCPCH Publications, 2003.

10 Royal Children's Hospital. Paediatric pharmacopoeia, 13th edn. Melbourne: Royal Children's Hospital, 2002.

11 Quick JD. Essential medicines twenty-five years on: closing the access gap. Health Policy Plan 2003;18:1-3.

12 WHO Policy Perspective on Medicines. WHO medicines strategy: 20002003. Geneva: WHO, 2000, http://www.who.int/medicines/library/ edm_general/6pagers/PPMO1ENG.pdf (accessed 21 May 2004).

13 Commission on Macroeconomics and Health. Macroeconomics and Health. Investing in health for economic development. Geneva: WHO, 2001, http:// www3.who.int/whosis/cmh/cmh_report/

report.cfm?path $=\mathrm{cmh}, \mathrm{cmh} \_$report\&language $=$english\# (accessed 18 June 2004).

14 Ruxin J, Paluzzi JE, Wilson PA, et al. Millennium project: emerging consensus in HIV/AIDS, malaria, tuberculosis, and access to essential medicines. Lancet 2005;365:618-21.

15 WHO. Selected topics in health reform and drug financing. Geneva: WHO, 1998, http://www.who.int/medicines/library/dap/who-dap-98-3/whodap-98-3.pdf (accessed 20 April 2005)

16 DFID HSRC. Access to medicines in under-served markets. London: DFID Health Systems Resource Centre, 2004, http://www.dfidhealthrc.org/ shared/publications/Issues_papers/ATM/DFID_synthesis_aw.pdf (accessed 20 April 2005)

17 Tan E, Cranswick N, Rayner C, et al. Dosing information for paediatric patients: are they really "therapeutic orphans"? Med J Aust 2003;179:195-8

18 Okuonghae HO, Ighogboja IS, Lawson JO, et al. Diethylene glycol poisoning in Nigerian children. Ann Trop Paediatr 1992;12:235-8.

19 Hanif M, Mobarak MR, Ronan A, et al. Fatal renal failure caused by diethylene glycol in paracetamol elixir: the Bangladesh epidemic. BMJ 1995;311:88-91.

20 Singh J, Dutta AK, Khare S, et al. Diethylene glycol poisoning in Gurgaon, India, 1998. Bull World Health Organ 2001;79:88-95.

21 O'Brien KL, Selanikio JD, Hecdivert C, et al. Epidemic of pediatric deaths from acute renal failure caused by diethylene glycol poisoning. Acute Renal Failure Investigation Team. JAMA 1998;279:1175-80.

22 Nahata MC, Pai VB, Hipple TF. Pediatric drug formulations, 5th edn Cincinnati, $\mathrm{OH}$ : Harvey Whitney Books.

23 Trouiller P, Torreele E, Olliaro P, et al. Drugs for neglected diseases: a failure of the market and a public health failure? Trop Med Int Health $2001 ; 6: 945-51$.

24 Global Forum for Health Research. The 10/90 report on health research 2003-2004. Geneva: Global Forum for Health Research, 2004, http:// www.globalforumhealth.org/pages/index.asp (accessed' 18 June 2004). 